\title{
Heritage and persistence: The case of the Kaiapoi fragment
}

Duration is the continuous progress of the past which gnaws into the future and which swells as it advances. And as the past grows without ceasing, so there is no limit to its preservation.

- Henri Bergson, 1907

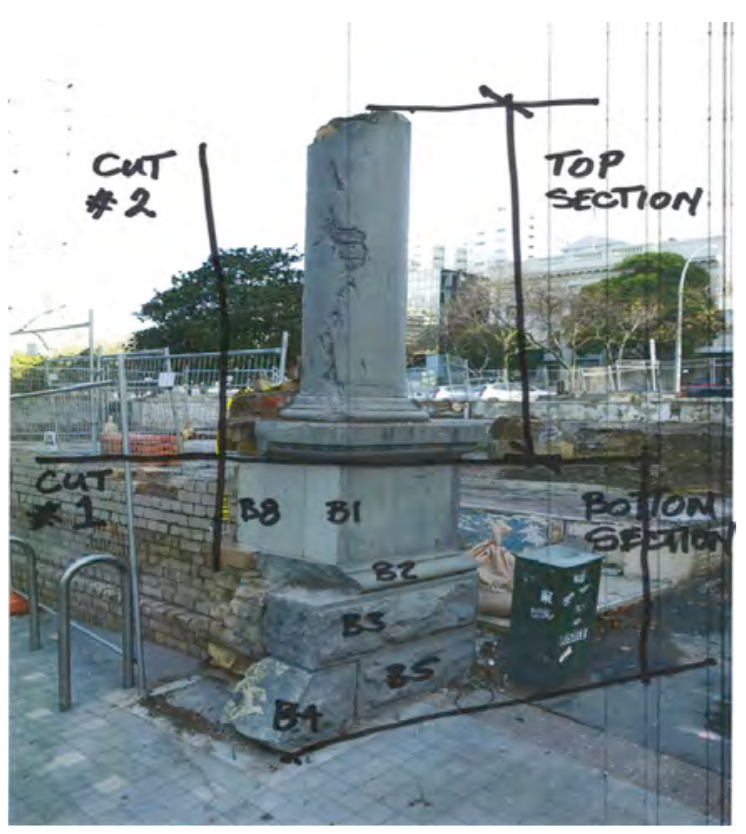

\section{Introduction}

Fig. 1 Reverb Consultancy (2016). Kaiapoi fragment, part designation and dismantling diagram [Photograph with pen-work]
This paper considers a small surviving portion of the Kaiapoi Woollen Company Building (see Fig. 1), a warehouse and offices constructed in the central business district of Auckland, New Zealand in 1913. Known as the Kaiapoi fragment, the incongruity of this persisting portion was foregrounded in 2016, when the Griffiths Holdings Building, a plain deco, two-storey commercial building immediately neighbouring where the Kaiapoi Woollen Company Building had previously stood on Wellesley Street West, was demolished to make way for a proposed underground train station. Dating from 1929, the Griffiths Holdings Building itself was deemed to hold, in the view of the heritage specialists involved, "little specific cultural heritage significance" (Reverb, 2016: 14). Yet, adjoining its eastern edge was an extraneous hanger-on: a fragment of the older Kaiapoi Woollen Company Building which had inadvertently remained fused with its newer neighbour. This had been the case since 1964, the date at which the Kaiapoi Woollen Company Building itself was demolished as part of the urban redevelopment of the area, for which the Bledisloe State Building was catalyst and complicating agent for street relations built up since the city's founding (see Fig. 2).

The Kaiapoi fragment, for its part, stood detached and solitary for a short period following the demolition of its neighbour, having survived both the demise of its progenitor, and the Griffiths Holdings Building-the vector that had transported it into a new century. 


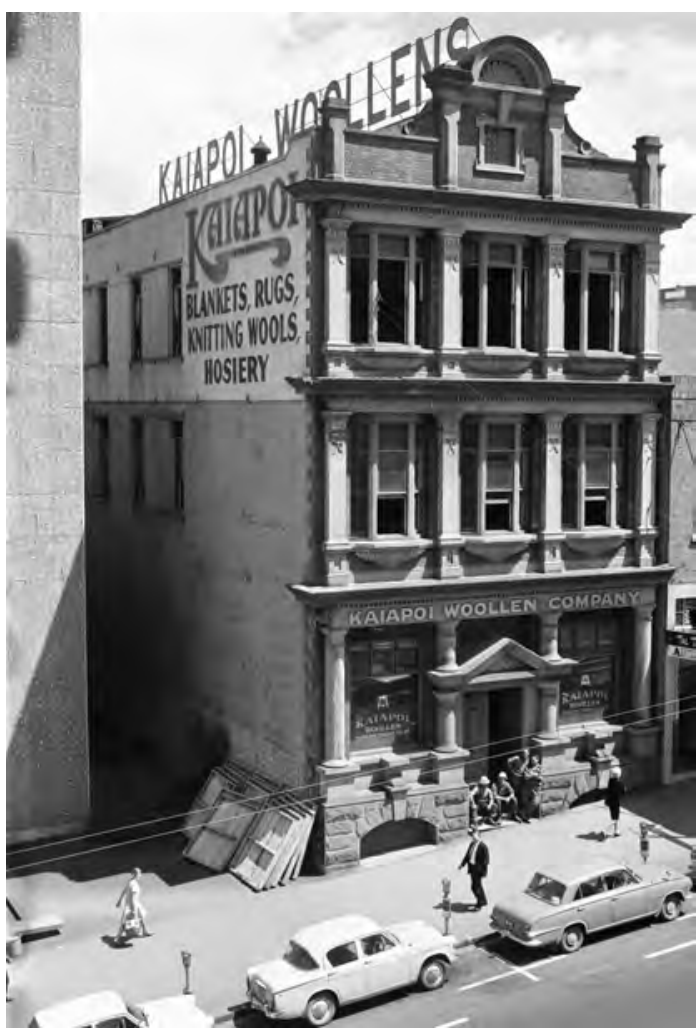

Fig. 2 Unknown (4 Nov 1964). "Showing the premises of the Kaiapoi Woollen Manufacturing..." [Photograph, Sir George Grey Special Collections, Auckland Libraries 7-A926]

Fig. 3. Evotia Photography (June 2016). Kaiapoi Fragment prior to dismantling and storage [Photograph, Reverb Consultancy Report]

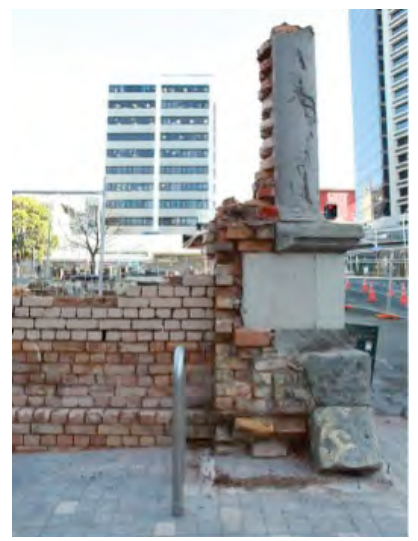

Our aim, in drawing attention to this fragment, is to explore questions of heritage persistence in the broader context of an inquiry into the nature of presence advanced particularly by Hans Ulrich Gumbrecht. ${ }^{1}$ While the notion of presence implies temporal immediacy-that which appears as present, now-Gumbrecht has emphasised, in particular, an insistent attribute that, we think, resonates with the tenacious persistence of the Kaiapoi fragment. As he writes: "By 'presence' I have meant-and still mean - that things inevitably stand at a distance from or in proximity to our bodies; whether they 'touch' us directly or not, they have substance" (2014: ix). Moreover, this substantiveness harbours a quality in excess of what can be analysed or interpreted: "the things-of-the-world, however we encounter them, also possess a [little considered] dimension of presence" (ix). This dimension, we propose, calls on questions of duration.

In fact Gumbrecht makes clear "present-ness" rests on broader temporal relations which are particularly fraught. Recognising a type of precarity in the contemporary present, Gumbrecht (2004 and 2014) argues that we are witnessing an emerging, yet still undefined, post-historicist chronotope. If the preceding, historicist chronotope is characterised by a "narrow present", one in which passing historical time provides immediately cogent bearings for acting on, and organising, an impending future, our current present, "inundated by memories and objects from the past", posits a truncated future, itself stalled and broadening inordinately (2014: 54-55).

In this, Gumbrecht's prognosis sits adjacent to a raft of contemporary cultural analyses exploring changing temporal orientations (see: Augé, 1995; Berlant, 2011; Crary, 2013) including a consideration of heritage, built space and shifting urban conditions. For instance, Andreas Huyssen's (2003) critique of a "memory boom", and with it, a "politics of memory" observes that, "the boundary between 
the past and present used to be stronger and more stable than it appears today" (2003: 1). If, for Gumbrecht, the future, as a thing flowing readily out of a present itself building causally on the past, appears blocked off, correspondingly for Huyssen, such a backlog takes the form of a chronic past-present permeability. Where history could once claim to stand in for the past, representing a more or less objective accounting of the nation and its evolving contours, and where memory, in turn, was aligned with subjective experience and recollection, something like a reversal has occurred. ${ }^{2}$ We see in fact, a displacement of what Huyssen terms a "hypertrophy of history" in the 19th century, to a "hypertrophy of memory" today-both personal and collective (2-3).

Reorientations in national traditions and a renegotiation of their sovereignty consequent to globalising forces are key. Where the past had been curtailed, more or less, within agreed national narratives, Huyssen sees a change in emphasis toward "memory without borders" and a surfeit of personal recollection (2003: 4). While canonical history is delegitimised, desire for narratives of the past continue to orientate our present, not least because modernity itself was predicated on a drive to learn from the past in pursuit of a progressively corrected future. Rather than a future-orientated present though, one capable of reading the past pedagogically, we end up with a past-orientated present.

To describe this compounded nature of the present and the past, Gumbrecht borrows Mikhail Bakhtin's (1895-1975) notion of the chronotope, a term characterising particular fusions of space and time evident across the history of the novel. To test the potential of Gumbrecht's claims, we explore Bakhtin's deployment of the chronotope and what underwrites it-dialogical exchange. We further investigate a foundational tenet of dialogue, developed by Henri Bergson (1859-1941), which conditions all space-time amalgamation-the dissolving power of 'duration'. Whilst not synchronous in their thinking, ${ }^{3}$ our extending of Bakhtin via Bergson aims to draw from Gumbrecht's consideration of "presentification” (2004: 94) a more acute attendance on temporal co-presence.

The issue of temporal co-presence is integral to issues of cultural heritage and heritage theory where materials from the past continue to have contemporary presence. Moreover, there has been uptake of Bakhtin's notion of the dialogical in contemporary views on heritage and anthropology, where relational dialogical ontologies create different kinds of "historicity" (Wirtz, 2016) and with them more creative heritage frameworks (Harrison, 2013; Holtorf, 2015). Dialogics, in these contexts, has been held to better engage with the complexities of contemporary challenges such as climate change, decolonisation and urban growth. Emphasising the work of duration in dialogics and chronotopes asserts, as Leonard Lawlor has characterised the distinction Bergsonism maintains over phenomenology, the “"primacy of memory' over a 'primacy of perception”" (2003: ix). It makes imaginable, again in Lawlor's words, a "non-phenomenological concept of presence", one whose ontology supplants being-in-the-present with a being in and of the past, and by extension, "being as the unconscious instead of consciousness" (x). While the full implications of Bergson's "spiritualisation", with its emphasis on image and memory over matter, sit beyond the scope of this paper, we sense value in them relative to questions of intangible value, a central but thorny area of concern for heritage. Further, we find, spanning these concerns, the possibility of offering a provisional anatomy of presence, one prompted by, despite its diminutive scale, the Kaiapoi fragment itself. 
With this framing in mind, the paper develops four aspects:

- firstly it backgrounds the context and circumstances of the Kaiapoi fragment;

- secondly, we link the Kaiapoi fragment to broadly theoretical and critical perspectives questing heritage orientation;

- thirdly, we extend these considerations via discourses centred on temporal relationships, an orientation we see as leading to an anatomy of presence;

- finally, the paper addresses a shift in our original perception of a precarious futurity for the fragment with a recently published proposal for the station forecourt.

The paper develops a dialogue across our divergent interests-themselves spanning heritage, policy, cultural theory and architecture-in a quest to think how, and under what conditions, presence both persists and is called towards futurity.

\section{The context and circumstances of the Kaiapoi fragment}

The Kaiapoi Woollen Company Building was a three storey, unreinforced double-skin brick masonry structure, topped with a gable roof in corrugated steel. It was a long narrow building primarily used for warehousing purposes, yet had an ornate, plaster-rendered, Edwardian Baroque façade serving the public on its (north) Wellesley Street frontage (see Fig. 4). Augmenting this primary street

Fig. 4 James D. Richardson (26 Jan 1928). "Looking west from Elliott Street up Wellesley Street West...1928" [Photograph, Sir George Grey Special Collections, Auckland Libraries 7-A9264-2141] presence, was the notable alternative face it directed eastward towards the commercial and civic heart of the city. Across the entirety of this lateral facade a blunt commercial appeal resting on nationalist sentiment spelt out: "Buy New Zealand Made Goods" (see Figs. 5 and 6).

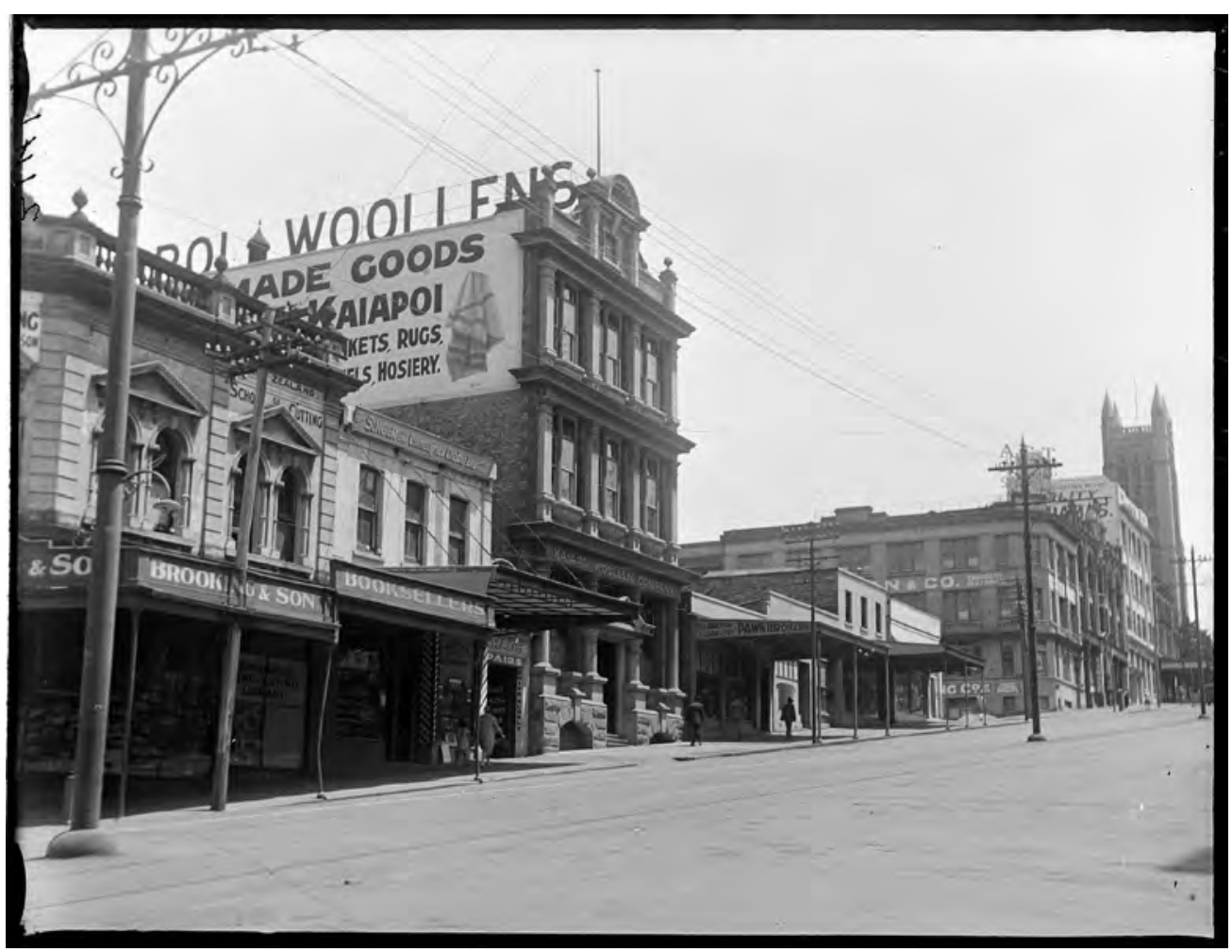




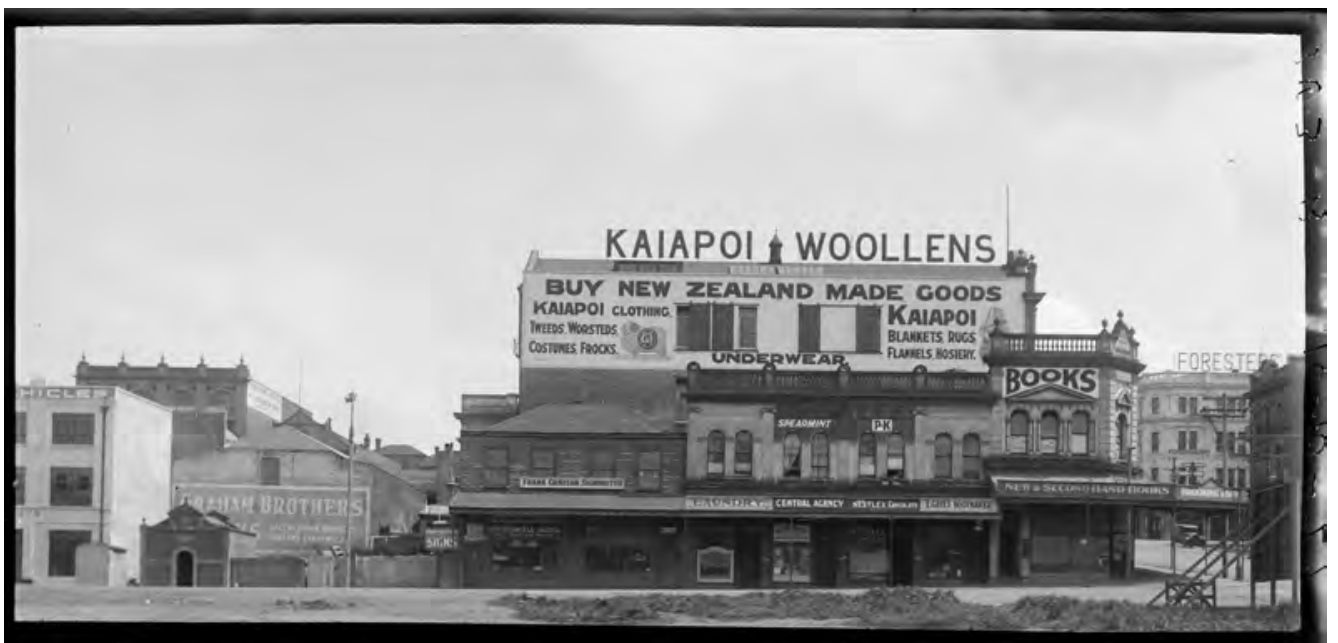

Fig. 5 RJames D. Richardson (16 Oct 1924). "Looking south west from Queen Street...1924" [Photograph, Sir George Grey Special Collections, Auckland Libraries 4-5644]

Fig. 6 James D. Richardson (1928). "Looking south along Wellesley Street West...1928” [Photograph, Sir George Grey Special Collections, Auckland Libraries 4-2176

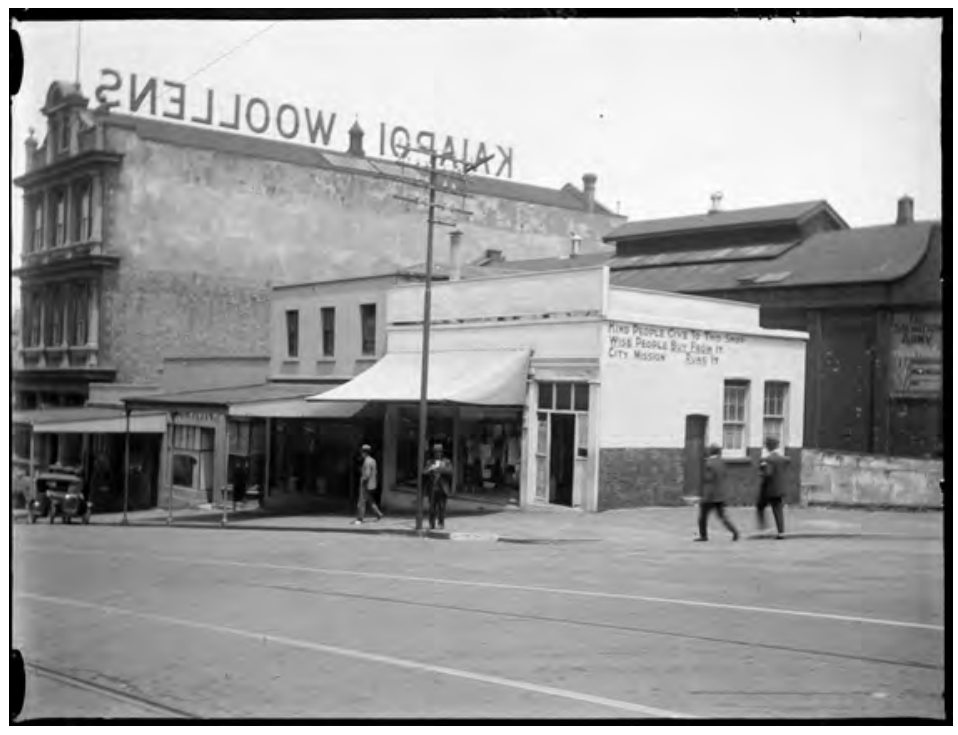

The Wellesley Street façade similarly signalled a nationalist appeal via its use of the Edwardian Baroque. Baroque classicism had, as Ian Lochhead has summarised, followed a long "domestication", remaking it firstly an English style, and subsequently the evolving architectural face of a conjoined nationalism of the British Isles (2004: 43). As such, Edwardian Baroque signalled a "progressive nationalism" which in turn became linked to empire, for which a "Wrenaissance" or "Imperial Baroque" was widely employed in colonial settings (43). Deployed in the context of Dominion status, realised in New Zealand in 1907, the routine use of the Edwardian Baroque in public and commercial architecture testified to both an assertion of self-governance (one rejecting Australian federalism) and imperial federation with Britain (45). Concomitantly, commercial nationalism, aligned with a shift from colonial extractive and progress industries (centred on resource removal and infrastructural expansion) to manufacturing economies, constitutive of Pakeha claims of self-reliance and "belonging here" (Belich, 2007: 361). Claims of progressiveness accompanied this manufacturing (emphasising technological innovation and product 'quality'), along with market competition (directed both internally and toward the imperial federation validitating Dominion). Auckland's Kaiapoi Woollen Building was a branch office of a business with premises in Christchurch, Wellington, Dunedin and London. 
The company name Kaiapoi is itself rich in place reference and appropriation. The wool for Kaiapoi woollens was sourced from the Waimakariri District and named after the small town and mill there. The town itself borrows its name from the pā situated just north, itself said to have been the largest fortified site for Ngāi Tahu in the South Island. Kaiapoi combines both kai (food/resources) and poi ("a light ball on a string of varying length which is swung or twirled rhythmically to sung accompaniment"; Māori Dictionary (n.d.)). Together they reference the challenging topographic situation of the pā whereby resources had to be 'swung in' to sustain settlement (Christchurch City Libraries, n.d.).

Whilst the Kaiapoi business in a merged form continued until 1978 (Puke Ariki online, n.d.) the Kaiapoi Woollen Company Building in Auckland was demolished in 1964. Factors influencing this demolition included plans for expanding the civic functions of the area for which the construction of the Bledisloe State Building, a new home for the local council, designed by then government architect Francis Gordon Wilson with Douglas Jocelyn “Jock” Beere was key. The Bledisloe State Building, completed in 1959, was celebrated at the time for "its one and a half acres $(6000 \mathrm{~m} 2)$ of glass", which faced both Bledisloe Lane to the east and the neighbouring Kaiapoi Woollen Company Building to the west (Shaw, 1991: 151). With a blank façade presented to Wellesley Street and the prioritising of lateral glazed viewing, at stake in the Bledisloe's nine storey rise was a radical contesting of the 'party' relation that had characterised the street up until that time. In this it advocated for, without seeing its promise completed, a different sense of the civic, the social and the temporal foundations of city places (see Fig. 7). While the contrary visions embodied by both buildings awkwardly faced each other for a period, the clash was resolved in favour of the outlook for the Bledisloe office workers in 1964 (see Fig. 2). Nevertheless, this produced no simple erasure, for it left in play for more than 40 years a gap approximating the Kaiapoi's prior footprint. The surviving Kaiapoi fragment, a persistent portion of the original building, was left connected to the 1929 Griffiths Holdings Building on the eastern party wall. As Reverb Consultants speculated:

The reasons for the fragment's survival when the Kaiapoi building was demolished in 1964 are unclear, but the column, the massive Coromandel base, and the attached brick backing, may have been left in situ out of caution for the structural support of the Griffiths Building. (Reverb 2016: 11)

The Kaiapoi fragment remains via its persistence a lingering pointer to the complex congregation of intent, precedent and time intersecting on Wellesley Street West.

\section{Theorising heritage}

The circumstances of the Kaiapoi Woollen Company Building have imbedded provocations for contemporary heritage practice, not least amongst these being its drastic reduction, at a material level, to a fragmented presence, and then, to no anchored presence at all. In this it mirrors the trajectory Huyssen identifies where the historical 'stuff' comprising narratives of nation are decommissioned by globalising forces leaving memories floating with uncertain relevance. Yet, the Kaiapoi fragment's presence at the junctures of different development periods in Auckland's history evidences material and temporality resisting erasure. In Huyssen's framing, at the very least it contributes to "palimpsests of space in the 


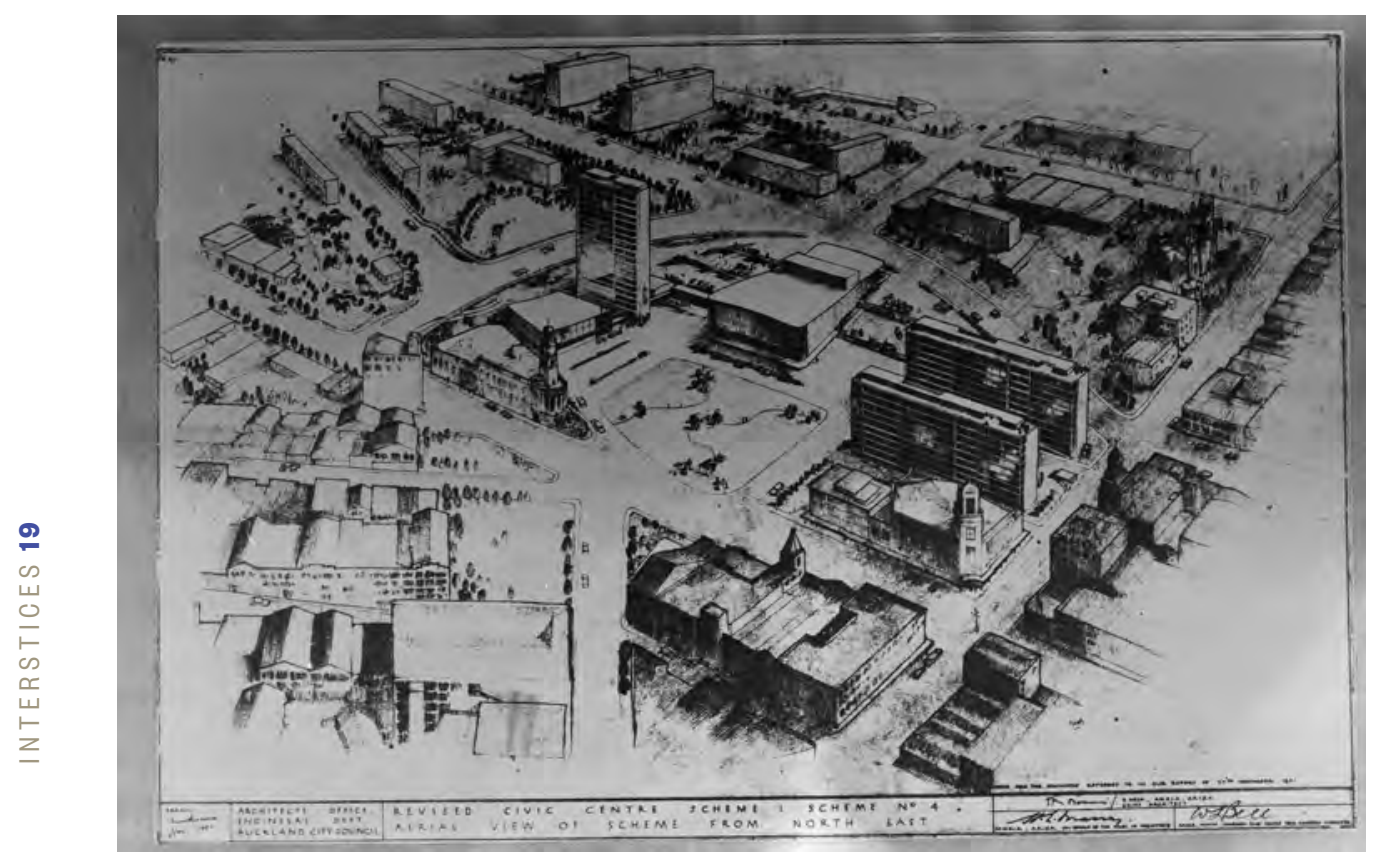

Fig. 7 Auckland City Council, Architects Office (1964). Civic Centre Plans [Print, Sir George Grey Special Collections, Auckland Libraries, 580-10204] urban imaginary" (7). As such, its peculiar mix of the tangible and the intangible calls for a creative adaptation of heritage practice and theory to better grasp what heritage futures can be imagined for and through it.

To clarify how heritage is being understood here, we see it as a practice that is about what is valued in the present (see Lowenthal, 1987), with its principal concerns being configurations of time, space, tangible materiality and intangible worth. Our aim, in reading such configurations via Gumbrecht's notion of presentification, Huyssen memory boom, and aspects of Bakhtin and Bergson's thinking, is to creatively and critically rework these heritage concerns. More broadly, we see this paper as participating in a comparatively nascent undertaking that applies cultural theory and/or critical lens on heritage and concepts of "heritage theory"-a project consistent with both the aims of the Association of Critical Heritage Studies (ACHS), itself formed in 2012 (see Morisset, 2017), and the Heritage Futures (HF) project, a UK Arts and Humanities Research Council research venture which understands heritage within a relational, dialogical framework. ${ }^{4}$

At stake for heritage seen this way, as Rodney Harrison, the HF chief investigator describes, are links to "broader issues of environmental, political and social concerns", links in fact that allow an emancipation and use of heritage "in more creative, transformative ways" (2013: 204-205). Here the usual concerns of preservation and conservation are read as forms of a present dispositif. Heritage is not only what reminds people of the past-with all the associative unreliability of those interpretations-but more significantly, it reveals the present and how these relationships form and intersect-an awareness Huyssen emphasises when he reminds that "the act of remembering is always in and of the present" (2003: 3). Whilst Huyssen is primarily concerned with memory here, heritage resources, as material evidence of the past within spatial fields, no less act as mnemonic devices in the present through their presence and their persistence.

Persistence, in all its mutable forms, is invariably what counters forgetting-the latter being, as Cornelius Holtorf, the UNESCO Chair on Heritage Futures notes, 
the loss-averting task the "conservation paradigm" sets as its principle aim (2015: 11). Further, as Holtorf finds in Adrian Forty's reading of Sigmund Freud, given the nature of memory in humans, forgetting must be "a freely decided and a deliberate act of putting something behind" (14). Correspondingly, "[d]emolition and subsequent emptiness cannot undo a persistent heritage site-except when nobody cares to remember it anymore" (14). Nevertheless, that the amplified interest in heritage over the last 200 years (Lowenthall, 1996; Harrison, 2013) and the related heritage boom have eventuated in vast increases of heritage places and objects being identified and protected is a response to late modernity's relationship to change and time. It is, in fact, Huyssen's "hyper trophies of history and memory" made material. Countering this loss aversion, Holtorf argues that "destruction and loss are not the opposite of heritage but constitutive of it" (2015: 15). Recognising the evolving, ongoing nature of what counts as heritage-its becoming as opposed to its being (as Holtrof puts it)-permits a creative engagement with the process of ongoing change. In this light, Bergson's concepts of duration and sympathy offer one way of moving conservation from a singular purpose of constraining loss to potentially more heterogeneous and sustainable practices. For its part, the Kaiapoi fragment complexly continues that from which it came while affirming the sympathetic potency of temporality itself.

\section{Heritage chronotopes}

More generally, if heritage is understood as a form of palimpsestic presence, indicative of a convergence of multiple times in one place, it is also suggestive of evolving overlays of condensed time-space constituting what amount to "heritage chronotopes". If the palimpsest connotes a textural condition, the notion of the chronotope correspondingly arises consequent to Bahktin's deployment of it, to account for certain generic patterns within the long compound history of the novel. To describe this heterogeneity, Bahktin sought to identify commonly ordered patterns of time and space making narratives comprehensible-an approach that has proved useful for heritage, which similarly works with divergent societal worlds. Writing in Russia around the 1920s, Bakhtin borrowed the term chronotope from biology, but saw in it both an alignment with Einstein's Theory of Relativity and a critique of Kantian philosophy. As he put it, in the context of literature:

Time, as it were, thickens, takes on flesh, becomes artistically visible: likewise, space becomes charged and responsive to the movements of time, plot and history. This intersection of axes and fusion of indicators characterises the artistic chronotope. (2000: 84 )

Consequently, chronotopes condense the plethora of discourses, utterances, and semiotic fragments making up specific collectives, and serve to make the worlds imagined in literary genres coherent and recognisable (Todorov, 1985: 83). Indeed, they are the variable building blocks of genres in so far as Bakhtin puts it, "[e]very genre has its methods, its ways of seeing and understanding reality" and this 'seeing' "delineates itself differently as space and time" (cited in Todorov, 1985: 83). Similar concerns are expressed within critical heritage theory by Harrison, in his work on the different domains of heritage practice (2015) - natural, cultural, archaeological, tangible, intangible, built, landscape - and in thinking through the overlapping of these ontological fields in what Harrison characterises as "heritage ontologies" (2018). 
Building on Bakhtin's concept of the chronotope, recent thinking on place relations, consistent with Huyssen's characterisation of a diversifying culture of memory, has emphasised a contesting state in which, at any one locale, chronotopes show up as contradictory and multiple, like so many monadic outlooks, closed off from each other, yet interacting dialogically across ontologically distinct borders. As Bahktin put it:

Chronotopes are mutually inclusive, they co-exist, they may be interwoven with, replace or oppose one another, contradict one another or find themselves in ever more complex relationships. The relationships themselves that exist among chronotopes cannot enter into any of the relationships contained within chronotopes. The general characteristic of these interactions is that they are dialogical (in the broadest use of the word). (2000:252)

In the context of heritage, a dialogical approach offers creative and future-orientated vantage and is conceivably what Harrison intends when speaking of heritage ontologies here:

We might think of these domains of heritage or modes of heritage making as particular ontologies of heritage, in the sense that they are concerned with different categories of being and different ways of assembling futures. (2018: 1378)

Additionally, applications of Bakhtin's recognition of both monadic worlds and a method for understanding how their differences might speak to each other are useful for the challenges heritage practices face moving from a largely Eurocentric ontological field to one where practitioners operate dialogically across the divergent ontologies of a decolonising world.

Useful for our thinking here about an anatomy of presence, is Tristian Todorov's (1985) recognition of aspects of German aestheticism being worked through by Bakhtin. If for Wilhelm Worringer empathy was central to aesthetic pleasure (98), for Bakhtin, empathy-putting oneself in the place of another or in external things-must be tempered least it induces a "loss of one's place", or subsumes the other's consciousness into one's own-a gesture akin to Hegel's dialectical overcoming as monologue (cited in Todorov, 1985: 109; see also 104). The dialogical is Bakhtin's counter to the dialectical, a means by which two consciousnesses may coexist by drawing empathetic identification back into the empathiser as a "self-other", a conditional identification Todorov translates as "exotopy" (Bakhtin cited in Todorov, 1985: 109; see also 99). In this notion of exotopy is a means for understanding, not just how two divergent subject positions coexist, yet inform each other; it also points to how divergent chronotopes convene, and indeed, suggests how consciousness itself is complexly chronotopic.

Given that Bakhtin developed exotopy relative to characterological concerns in literature, how might it operate in broader inanimate domains? Certainly, the meaning and place of material artefacts in social worlds has long preoccupied archaeologists and anthropologists. More recently, the "material turn", as Dan Hicks argues, has provided multiple frameworks for "fixing the meaning or social use of objects in particular moments in time", yet a more productive means for dealing with the "permeabilities of boundaries between humans and non-humans" might be to view "things as events" (2010: 81). This notion anticipates Holtorf's proposition that heritage artefacts are not entities fixed at single times 
but things in long sequences of becoming. This eventful nature of things similarly corresponds with Gumbrecht's assertion that aesthetic experience, itself richly material, arises as an "oscillation (and sometimes as an interference) between 'presence effects' and 'meaning effects'" (2004: 2). This oscillation in fact may be thought of as exotopic encounters between worlds of meaning, a proposition we follow below.

\section{An anatomy of presence}

Drawing heritage into the question of presence, Gumbrecht alerts us to the possiblity of experiencing and thinking things doubly: on one hand through meaning attribution (a prevailing drive in modern Western thought); and on the other, via presence effects. In relation to historical objects, as Gumbrecht usefully deploys as examples, the former involves seeing them as symptoms of the past, symptoms capable of explaining the present. The latter, displacing analysis and meaning, effects a "historical presentification" that empathetically transports:

The desire for presence makes us imagine how we would have related, intellectually and with our bodies, to certain objects [...] if we had encountered them in their own historical everyday worlds. (124)

This "historical imagination", as he terms it, shares with aspects of aesthetic experience the capacity to break with everyday situations, thereby holding open a pause prior to closure of meaning attribution (125). Historical objects, themselves incongruous with everyday immediacy, induce a "crossing of the life world threshold of our birth", thereby complexifying the present with an empathetic experience of other space-times beyond our own. The distance-gathering capacity of such presentification is "deictic, rather than interpretive"-in other words, it is context-dependent (128). Presence then, as that which breaks, counterintuitively, with the surety of the immediately given, calls up a deictic demand, a reading-into that oscillates joyfully and painfully between "losing and regaining intellectual control and orientation" (128).

Yet how might presence as oscillation in orientation be reconciled with the notion of the chronotope? Our earlier explication of the dialogical, itself patently deictical in its to-and-fro interlocation, is suggestive. Bakhtin considers such deictical co-presence in the context of the type of reception literature makes possible. At stake, he argued, in any encounter between a text and a reader is the invention of "a special creative chronotope" (2000: 254) condensing the work with the lived determinants of its reception-an encounter enacted exotopically. Presence in this context amounts to a creative flare-up at the intersection of chronotopes, a dialogic exchange that itself immediately re-consolidates chronotopically.

Bahktin's creative vitalism-building on a communicative potency spanning chronotopes-itself invites comparison with Henri Bergson's own vesting of sense in a creative vitality exhibited by temporality. Here, by way of comparison is Bergson's characterisation of one half of any dialogic exchange-listening:

I can indeed understand your speech if I start from a thought analogous to your own and follow its windings with the aid of verbal images which are so many signposts that show me the way from time to time. (1991: 125) 
More broadly, dialogue suggests a parallelism between interlocutors in which each pursues analogies seeking an adequate correspondence with the mobility of the other's thought-forms of mobility always in excess of language itself. While language usage and social convention might well supply sufficient habits to render these analogous labours minimal, in fact, to be present to dialogue in its fullest capacity demands a shift from habitual experience to, what Bergson termed "attentive perception", a mode of sensing brought on by lapses of immediate understanding or recognition (1991: p104-105; see Bergson’s Fig. 1). To recognise habitually, or immediately as Bergson put it, is to know how to act-a conversion that turns perception into sensorimotor responses, that in turn, extend a world out horizontally in what amounts to the building of a consistent and reliable 'reality'. When presented with something unrecognisable or unidentifiable, perception cannot be extended into action but must follow another route-temporal excursions into memory in search of prior descriptions or images able to adequately equate with, and therefore elucidate, particular unknowns in the present. Dialogue then, can be schematised as unfolding across two dimensions: a horizontal extension of locution by linked up, common-sensical utterances; and a vertical leap in which a listener seeks a more demanding grasp of the source or essence driving another's utterances. As David Lapoujade summarises this use of analogy in the latter by Bergson:

The circuit of recognition goes from idea to idea, following a symmetry, a spiritual work of analogy. Analogy is memory throughout. We recognise the other in us, and this allows us to recognise ourselves in the other. (2018:54)

In Bergson's intuitive analogy there is an internalisation approximating the exotopic exchange we find in Bakhtin. Further, Bergson schematises this complex recognition, as firstly, a feeling inward for the analogous, and secondly, via sympathy, a to-and-fro testing for an adequate symmetry between what is manifest outwardly and what is inward-in other words, a correspondence in what Bergson sees as the "virtual objects" underpinning both (Lapoujade, 2018: 53). Beyond an interlocation between persons, what intuition finds in its vertical excursion is the action of duration reworking life itself, a duration not just internal to human consciousness, but to matter in general. Moreover, analogy is a solvent dissolving other space-time amalgams, so that via sympathy we are capable of being transported into the durational interior reality of other entities-or what can be read as chronotopes. In short, intuition glimpses how duration is conserved inwardly, but also, via an affective sympathy, how the movements of matter beyond us are conserved. Hence, this sounding of the vertical dimension of temporality runs past the limits of consciousness, leaning into a pure memory, or durational whole that envelopes all the fluctuations of duration making the living distinction of matter present as such. Again, as Lapoujade summaries Bergson's insights:

[...] it is man who, thanks to intuition, enters into 'contact' with the nonhuman movements, memories, and consciousness deep inside him. There is basically nothing human about man. It is because intuition reaches the nonhuman tendencies in man that it can give the reciprocal impression of humanizing the nonhuman. (47)

So while Bakhtin says, in relation to dialogic exchange between chronotopes, that everything, in the final analysis, comes up "against the human being" (253), 
Fig. 8 Reverb Consultancy (2016). Kaiapoi fragment, elevational diagramme [Pen-work]
Bergson invites us to recognise this humanness as itself being built in and out of the chronotopic fluctuations variously arising with the open movement of duration itself. Further, if presence, via intuition and sympathy, draw awareness towards this openness-itself radically reorienting in anxiety-inducing as well as joyful ways-Gumbrecht's attendance on it as antidote to an excessive dependence on the intellectualising work of interpretation exhibits a Bergsonian legacy to the extent that for Bergson, intelligence is the evolutionary capacity in humanity that drives towards a disequilibrium in the attachment to life. An advocacy of presence today stands out precisely as a call for a renewed attachment to life as such, an attachment, as Bergson (1935/2013) framed it, beyond religiosity per se, and closer in motivation, if not actuality, to mysticism.

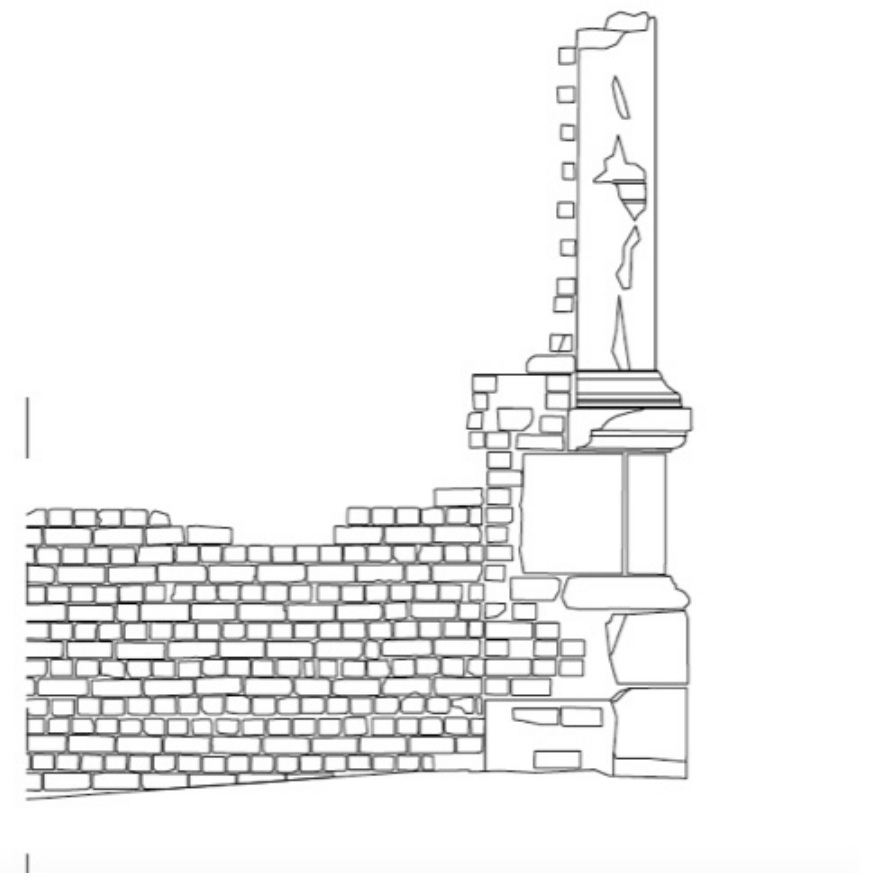

\section{What presence the Kaiapoi fragment?}

How then to read, sympathetically, the chronotopic intersection playing out in the Kaiapoi fragment? It stands as a remnant of an older nationalism indexed to imperial federation-a past configuration with persisting echoes. More generally, like so much bound centripetally within what Saskia Sassen has referred to as "the spatio-temporal order of the nation-state", centrifugation by global forces continues to reorder and ecilipse much that counted within the older nationalisms (2006: 398). In commencing this paper we worried that the Kaiapoi fragment was set to join the sea of such eclipsed matter. Yet the loss of the material object in fact provided an ongoing presence via a sympathetic recounting of its modes of persistence. Certainly, the absence of its materiality is not the same as an absence of its presence. For no lesser a reason, as Bergson has shown, memory is the very precondition for duration and is what persists absolutely. Initially, whether the Kaiapoi fragment would find a tangible, settled public presence again was uncertain. At one level this was peripheral to our exploration, relative to heritage, of a non-phenomenological concept of presence. Nor did we set out to argue for the Kaiapoi fragment's retention or resituating someplace. Instead, 
we found in its precarity a provocative analogue for a truncated futurity more generally, and in turn, a prompt for a more critical theoretical vantage on what heritage enacts in conserving the past.

Nevertheless, time is capable of revising expectation, and in 2018 Auckland Transport, the agency determining the form of the new underground station, which in turn set in train the series of circumstances foregrounding the Kaiapoi fragment's lone standing, released visualisations showing the fragment's restoration seemingly at its original location (see Fig. 9). Freed of both a party wall and a building as body, the fragment, once an engaged column, is shown standing in the round. This disengagement approximates a truncated column about which a travelling public will circle on route to and from the underground. While such a configuration would seem to offer reduced potential for interpretation-with nothing more of the Kaiapoi Woollen Company Building remaining-offered instead is a strong conduit for sympathy in the sense we have developed here. While dialogical exchange depends on the to-and-fro work of analogous presentification, the acutely reduced Kaiapoi Woollen Company Building presences an encounter with the dissolving power of duration itself.

Fig. 9 Andrew Douglas (2019). Restored Kaiapoi fragment at the entry to the new Aotea Station (with the Bledisloe Building in background) [Pencil drawing based on AT's City Rail Link Aotea Station Flythrough. See - https://www. cityraillink.co.nz/crl-stations-aotea/]
More positively, it would seem to enact, in its acute reduction, what Bakhtin has referred to as the "real-life chronotope of meeting", a ubiquitous motif in "spheres of public and everyday life" where particular convergences of space and time shift the very course of things (2000: p98-99). Certainly the notion of encounter has been pivotal to our reading of the fragment: more broadly, how does the present meet the future and the past; how do chronotopes meet dialogically; 
and, more specifically, how might the Kaiapoi fragment meet a future? The motif of meeting is not an incongruous issue in this case, given that the fragment itself marks the pivotal intersection of both the party wall and street facade, those mechanisms by which buildings meet other buildings and varying publics over time.

Given this enduring "chronotopicity" and its becoming column-like, Joseph Rykwert's The Dancing Column: On Order in Architecture (1999) offers a final vantage on the standing remainder of the Kaiapoi fragment. On the metaphoric shaping of matter transported by classicism, he writes: "It elaborates the primal identification of the standing body with an upright post" (373). Moreover, the two-term logic of metaphor- "this is like that"-is compounded by a third: "a body is like a building and the building in turn is like the world" (373). So too can architecture "speak in figures" consistent with an archaic "mimetic heritage" (p373-374). If, as Rykwert reminds, this figural dimension was progressively lost to Western architecture and the arts from the 17th century, and called for in fact is a rehabilitation of mimetic empathy (388). Intercourse and not order is the lesson Rykwert draws from the "mimetic artifacts" favoured by classicism. Against " "plain reading"” and a mute architecture-in other words, reading and building that are "univocal [and] antimetaphoric"-he calls for that which sustains renewed "dialogue and touch" (391).

With the Kaiapoi fragment we have resisted both a plain reading of it as artefact and an analogous one of it as 'heritage' more broadly. Instead we have sought, via sympathy, to make from not very much, a conduit running deep into duration itself. In contrast to the centrifugal relay linking bodies to columns, columns to buildings and buildings to world, we have sought to reverse-engineer ascending empathetic desire, an ascendance Bergson (1963) himself critiqued in the affective belonging justifying nationalism. As such, the social instinct of family is expanded into the social obligation of nation no less than religion, a course seemingly running toward openness but in fact modelling closure at multiple levels (1963: 32; see also Alexandre Lefebvre's "picture of morality" in Bergson, 2013: 4). If at stake in family and nation, ideally, is love, but one resting on modes of constancy, Bergson sees in duration a contrary and immediate affection. This is experienced variably according to an intuited sympathy, itself creatively contacting the plethora of temporalities spanning the human and the nonhuman (Lawlor, 2003: 62). Presence, in its common understanding speaks to what Bergson understood as "attention to life", those momentary engagements with the immediate present that counter the human capacity to dilate experience through dream and reverie, or, conversey, build an intellectual indifference to immediacy. Sympathy instead points to a deepening of attention and a richer engagement, one necessary to an "attachment to life" (Lapoujade, 2018: p59-63).

The Kaiapoi fragment seems capable of attuning us to such an attachment to life. In the context of globalisation's unbundling of the "unitary time-space of the national", a range of "diverse spatio-temporal orders", otherwise invisible emerge (Sassen, 2006: 398). Consequently, the question of how to maintian attachment to forms of life shaped by such unbundling is pressing. More than a thing to be passed by indifferently, the persistent standing of the Kaiapoi fragment suggests a dance with time that attachment richly visits upon us. 


\section{Declaration of Interest}

We wish to disclose that our interest in the Kaiapoi fragment stems from a connection with the heritage professional responsible for its continued existence. In mid 2016 Bruce Petry, as director of Reverb Consultancy, arranged for the fragment to be retained and stored for future possible use shortly before his death. Subsequently, for a brief period, Andrew Douglas acted as director of Reverb Consultancy for the purpose of closing the business. Neither authors were party to recommendations or decisions by Reverb Consultancy related to the Kaiapoi fragment. We dedicate this paper to Bruce whose sympathy and passion for heritage inspired it.

\section{Acknowledgement}

We further wish to thank anonymous review of both the presentation abstract and an earlier iteration of this paper. Their insights have assisted us considerably. 


\section{REFERENCES}

Augé, M. (1995). Non-place: Introduction to an anthropology of supermodernity (J. Howe, Trans.). London, England and New York, NY: Verso.

Bakhtin, M., Holquist, M. (Ed.) (2000). The dialogical imagination: Four essays by M.M. Bakhtin (C. Emerson \& M. Holquist, Trans.). Austin, TX: University of Texas Press.

Belich, J. (2007). Making peoples: A history of New Zealanders from Polynesian settlement to the end of nineteenth century. Auckland: Penguin.

Benton, T. (2010). Understanding heritage and memory.

\section{ENDNOTES}

1 This paper was originally delivered orally at the Interstices Under Construction Symposium + Colloquium: Presence, an event and explore Hans Ulrich Gumbrecht's work on the phenomenon of presence at the University of Auckland, NZ.

2 Also see Lowenthal (1987) on distinctions between 'history' and 'heritage' and the relationship of the present to these.

3 While Bakhtin was separated from Bergson by about a generation, and by language and geography, his awareness of Bergson's thinking likely arrived by way of secondary sources initially. Despite debates over the degree of sympathy they may have shared, Daphna ErdinastVulcan (2013) has argued that Bergson's appeal to intuition as method and his "project of [open-ended] temporalization", likely formed the foundation upon which the thinking of Bakhtin and his circle was built (19 \& 224).

4 Sitting squarely within the ACHS schema, the HF project holds "a plural notion of heritage ontologies-understood as the world making, future assembling capacities of heritage practices of different kinds - and the ways in which different heritage practices might be seen to enact different realities and hence to assemble radically different futures".

(Heritage Futures, 2015) contemporary culture. New York, NY: Columbia University Press.

Harrison, R. (2013). Heritage: Critical approaches. New York, NY: Routledge.

Harrison, R (2015). Beyond 'Natural' and 'Cultural' Heritage: Toward an ontological politics of heritage in the age of anthropocene. Heritage \& Society, 8:1, 24-42.

Harrison, R., Rose, D. B. (2010). Intangible heritage. In T. Benton (Ed.), Understanding Heritage in Practice (p 238-276). Manchester, England: Manchester University Press.

Heritage Futures (2015). Retrieved from https://heritagefutures.org/about/

Hicks, D (2010). The materialcultural turn: Event and effect. In D. Hicks \& M. Beaudry (Eds.), The Oxford handbook of material culture studies (p 25-98). Oxford, UK and New York, NY: Oxford University Press.

Holtorf, C (2015). Averting loss aversion in cultural heritage. International Journal of Heritage Studies, 21:4, 405-421.

Huyssen, A. (2003). Present pasts: Urban palimpsests and the politics of memory. New York, NY: Columbia University Press.

Lapoujade, D (2018). Powers of time: Versions of Bergson (A Goffey, Trans.). Minneapolis, MN: University of Minnesota Press.

Lawlor, L. (2003). The Challenge of Bergsonism. London, UK: Continuum

Lefebvre, A. (2013). Human rights as a way of life: On Bergson's political philosophy. Stanford, CA: Stanfrod University Press.

Lowenthal, D. (1987). The heritage crusade and the spoils of history. Cambridge, England: Cambridge University Press.

Māori Dictionary (n.d.). "Poi” entry. Retrieved from, https:// maoridictionary.co.nz/search? idiom $=$ \&phrase $=$ \&proverb $=$ \&loan=\&histLoanWords = \&keywords $=p o$

Morisset, L. (2017). President's welcome. At, the Association of Critical Heritage Studies website. Retrieved from https:// www.criticalheritagestudies.org/ presidents-welcome.
Puke Ariki (n.d). "Kaiapoi” entry. Retrieved from https://collection. pukeariki.com/persons/3157

Reverb (2016). Kaiapoi

Building Fragment heritage report. Unpublished report commissioned by Auckland Transport.

Salmond Reed Architects (2014). Griffiths Building Wellesley Street, Auckland: Heritage impact assessment. Unpublished report commissioned by Auckland Council.

Sassen, S. (2006). Territory, authority, rights: From Medieval to global assemblages. Princeton, NJ and Oxford, UK: Princeton University Press.

Shaw, (1991). New Zealand architecture: From Polynesian beginnings to 1990. Auckland: Hodder \& Stoughton Press.

Todorov, T. (1985). Mikhail Bakhtin: The dialogical principle (W. Godzich, Trans.). Minneapolis, MN: University of Minnesota Press.

Wilson, S. (2018). What lies beneath: Auckland City Rail Link plans unveiled. NZ Herald, 3 March 2018. Retrieved from, http://www.nzherald. co.nz/nz/news/article.cfm?c id=1\&objectid=12002410.

Wirtz, K. (2016) The living the dead and the immanent: dialogue across chronotopes. HAU: Journal of Ethnographic Theory 6 (1), 343-369.

Witcomb, A. \& Buckley, K. A. M. (2013). Engaging with the future of 'critical heritage studies': Looking back in order to look forward. International Journal of Heritage Studies, 19:6, p 562-578.
Gumbrecht, H. U. (2004).

The production of presence: What meaning cannot convey Stanford, CA: Stanford University Press.

Gumbrecht, H. U. (2014). Our broad present: Time and 